\title{
Selected topics from the 23rd International Colloquium on the Dynamics of Explosions and Reactive Systems, Irvine, California, USA, July 24-29, 2011
}

\author{
L. Bauwens - S. Dorofeev
}

Published online: 19 April 2013

(C) Springer-Verlag Berlin Heidelberg 2013

This issue contains selected papers that were presented at the 23rd International Colloquium on the Dynamics of Explosions and Reactive Systems, held in Irvine, California, USA, July 24-29, 2011. The biennial International Colloquium on the Dynamics of Explosions and Reactive Systems is the reference meeting focusing specifically on dynamic aspects of reactive systems.

The local organization was headed by Derek Dunn-Rankin (Department of Mechanical Engineering, University of California, Irvine). The program committee was chaired by Yei-Chin Chao (National Cheng-Kung University, Taiwan), and co-chaired by Matei Radulescu (University of Ottawa, Canada), with the assistance of Jeong-Yeol Choi (Pusan National University, Korea), Andrew Higgins (McGill University, Canada), Ulrich Maas (Karlsruhe Technical University, Germany), Francesco S. Marra (CNR Istituto di Ricerche sulla Combustione and Universita del Sannio, Italy), Akiko Matsuo (Keio University, Japan), Sergey P. Medvedev (N.N. Semenov Institute for Chemical Physics, Russia), Eric L. Petersen (Texas A \& M University, USA), Steven S. Shy (National Central University, Taiwan), HongGye Sung (Korea Aerospace University), Jennifer X. Wen (Kingston University, UK), Vigor Yang (Georgia Tech, USA) and Fan Zhang (Defence Research Establishment Suffield, Canada).

L. Bauwens $(\bowtie)$

Department of Mechanical and Manufacturing Engineering, University of Calgary, Calgary, AB T2N 1N4, Canada

e-mail: bauwens@ucalgary.ca

\section{S. Dorofeev}

FM Global Research,

1151 Boston-Providence Turnpike, P.O. Box 9102, Norwood, MA 02062, USA

e-mail: sergey.dorofeev@fmglobal.com
Several hundred participants attended the conference and delivered 220 oral presentations and presented over 100 posters on explosions, detonations, ignition, turbulent combustion and other topics in combustion.

As in previous years, presenters at the conference were encouraged to submit their work to the most suitable among a choice of journals. The current volume includes papers dealing with combustion in high speed flow and shock waves, detonation and deflagration-to-detonation transition, whose authors elected to submit to Shock Waves. Submissions were subjected to the regular rigorous review process, resulting in the selection featured in this volume.

The current issue includes five articles on gaseous detonations including DDT and ignition, one on spherical explosions, and three on combustion in heterogeneous media. Geographically, two papers originated from France, two from Russia, one respectively from Japan, Poland, the USA, Germany and Canada.

Finally, we wish to thank the authors who submitted their papers to this issue and also, the numerous reviewers whose help was crucial in ensuring the high quality of the papers that appear here. 